\title{
A Note on a Nonlinear Minimax Location Problem in Tree Networks*
}

\author{
Richard L. Francis**
}

(May 16, 1977)

\begin{abstract}
We present properties some new derivations of properties of a nonlinear version of a minimax tree network location problem. The provide necessary and sufficient conditions for optimality, a means of computing the optimum objective function value, and a means of constructing the unique optimum location.
\end{abstract}

Key words: Facility location; location theory; minimax; networks.

\section{Introduction}

The purpose of this note is to provide new proofs for properties, established by DEARING [4], ${ }^{1}$ of a quite general nonlinear minimax location problem; these proofs appear to give additional insight into the mathematical nature of such problems. As a natural consequence of the approach we use, we obtain as well a new family of equivalent conditions for optimality to the problem.

So as to state the problem, consider a finite undirected tree network with positive arc lengths. We denote by $T$ an imbedding of the given tree (e.g., a planar imbedding such as a road network) having rectifiable arcs, so that it is meaningful to speak of points on the ares as well as at vertices.

For every pair of points $x$ and $y$ in $T$, we suppose the shortest-path distance between $x$ and $y, d(x, y)$, is well defined, as in reference [2]. This distance has the customary metric properties for every $x, y \in T$, that $d(x, y) \geq 0$, that $d(x, y)=0$ iff $x=y$, and that $d(x, y)=d(y, x)$; also $d(x, y) \leq d(x, z)+d(z, y)$ for every $x, y$, $z \in T$.

The problem of interest is as follows. Suppose "existing facilities" are at distinct vertex locations $v_{1}, \cdots$, $v_{m}$ in the tree, and that a "new facility" is to be located at a point $x$. For each vertex $v_{i}, f_{i}\left[d\left(x, v_{i}\right)\right]$ is a "cost" or a "loss" incurred, increasing with the distance between $x$ and $v_{i}$, and

$$
f(x) \equiv \max \left\{f_{i}\left[d\left(x, v_{i}\right)\right]: 1 \leq i \leq m\right\}
$$

is the maximum loss. The problem of interest is to find $x^{*}$ in $T$ to minimize $f$ defined by (1); we call any such $x^{*}$ a minimum of $f$. One may wish to employ such an approach when it is more important to provide quick service than to minimize total cost.

So as to state the problem more precisely, define $\delta_{i}=\max \left\{d\left(u, v_{i}\right): u \epsilon T\right\}, 1 \leq i \leq m$. Also we define $f^{*}$ $\equiv f\left(x^{*}\right)$; continuity and compactness considerations assure the existence of a minimum of $f$. We assume $f_{i}$ is a strictly increasing, continuous function, with domain $\left[0, \delta_{i}\right]$, for $1 \leq i \leq m$. The assumed properties for each $f_{i}$ are quite weak, compared to assumptions in earlier related literature. Dearing was apparently the first to solve the problem using only these assumptions; previous work assumes the functions $f_{i}$ to be linear, and is discussed by DEARING and FRANCIS [2].

Subsequent to the analysis we indicate in some detail how our results differ from Dearing's.

\section{Analysis}

The following definitions facilitate the analysis:

$$
\begin{aligned}
M & \equiv\{1,2, \cdots, m\} \\
M P & \equiv\left\{i \in M: f^{*} \leq f_{i}\left(\delta_{i}\right)\right\} \\
M S & \equiv\left\{i \in M: f_{i}\left(\delta_{i}\right)<f^{*}\right\}
\end{aligned}
$$

* An invited paper. This research was supported in part by the Army Research Office, Triangle Park, NC under contract number DAHCO4-75-G-0150.
** Present address: Department of Industrial and Systems Engineering, University of Florida, Gainesville, Florida 32611.
${ }^{1}$ Figures in brackets indicate the literature references at the end of this paper 


$$
\begin{aligned}
\alpha^{\prime} & \equiv \max \left[f_{i}(0): i \in M P\right] \\
\alpha & \equiv \max \left[f_{i}(0): i \in M\right] \\
\eta^{\prime} & \equiv \min \left[f_{i}\left(\delta_{i}\right): i \in M P\right] \\
\eta & \equiv \min \left[f_{i}\left(\delta_{i}\right): i \in M\right] \\
f^{\prime}(x) & \equiv \max \left[f_{i}\left[d\left(x, v_{i}\right)\right]: i \in M P\right], \text { for all } x \in T
\end{aligned}
$$

We remark that any $f_{i}$ with $i \epsilon M S$ is a secondary function in the sense that it may be deleted from the definition of $f$ without changing $f$, that is,

$$
f(x)=f^{\prime}(x)
$$

for all $x \in T$. However, functions $f_{i}$ where $i \epsilon M P$ are primary functions in the sense that $f$ may be changed if any such function is deleted.

The above definitions lead to

REMARK 1: (a) MP $\neq \phi$.

$$
\begin{aligned}
& \text { (b) } \alpha^{\prime} \leq \alpha \leq f^{*} \leq \eta^{\prime} \text {. } \\
& \text { (c) We may assume } \alpha<\eta \text { without loss of generality. }
\end{aligned}
$$

Proof. (a) The proof is simple and we omit it.

(b) The proof is trivial except for $\alpha \leq f^{*}$. Let $f\left(x^{*}\right)=f^{*}$.

We then have

$$
f_{i}(0) \leq f_{i}\left[d\left(x^{*}, v_{i}\right)\right] \leq f\left(x^{*}\right)=f^{*}, \quad 1 \leq i \leq m,
$$

giving $\alpha \leq f^{*}$.

(c) If $\alpha \geq \eta$ then there exist functions $f_{i}$ and $f_{j}$ such that $f_{i}(0) \geq f_{j}\left(\delta_{j}\right)$, thus $f_{j}(x) \leq f_{j}\left(\delta_{j}\right) \leq f_{i}(0) \leq f_{i}(x)$ for all $x \in T$, and so the function $f_{j}$ may be deleted from the definition of $f$ without changing $f$.

The following remark establishes properties of functions which occur repeatedly in the subsequent analysis. The proof is straightforward but tangential to the main body of the development, and we relegate the proof (of a more extensive form of the remark) to the appendix.

REMARK 2: Let $\{\mathrm{j}, \mathrm{k}\} \subset \mathrm{M}$ with $\mathrm{j} \leq \mathrm{k}$. Define the strictly increasing, continuous function $g_{j k}$, whose domain $\left[\mathrm{a}_{\mathrm{jk}}, \mathrm{b}_{\mathrm{jk}}\right]$ is nonempty by Remark $1(c)$, by

$$
\mathrm{g}_{\mathrm{jk}}(\mathrm{z})=\mathrm{f}_{\mathrm{j}}^{-1}(\mathrm{z})+\mathrm{f}_{\mathrm{k}}^{-1}(\mathrm{z}),
$$

where

$$
\begin{aligned}
\mathrm{a}_{\mathrm{jk}} & \equiv \max \left[\mathrm{f}_{\mathrm{j}}(0), \mathrm{f}_{\mathrm{k}}(0)\right], \\
\mathrm{b}_{\mathrm{jk}} & \equiv \min \left[\mathrm{f}_{\mathrm{j}}\left(\delta_{\mathrm{j}}\right), \mathrm{f}_{\mathrm{k}}\left(\delta_{\mathrm{k}}\right)\right] .
\end{aligned}
$$

Also define $\mathrm{L}_{\mathrm{jk}}$ and $\beta_{\mathrm{jk}}$ by

$$
\begin{aligned}
& L_{j k} \equiv \begin{cases}\mathrm{f}_{\mathrm{j}}^{-1}\left[\mathrm{f}_{\mathrm{k}}(0)\right]>0 & \text { if } \mathrm{f}_{\mathrm{j}}(0)<\mathrm{f}_{\mathrm{k}}(0) \\
0 & \text { if } \mathrm{f}_{\mathrm{j}}(0)=\mathrm{f}_{\mathrm{k}}(0) \\
\mathrm{f}_{\mathrm{k}}^{-1}\left[\mathrm{f}_{\mathrm{j}}(0)\right]>0 & \text { if } \mathrm{f}_{\mathrm{j}}(0)>\mathrm{f}_{\mathrm{k}}(0)\end{cases} \\
& \beta_{\mathrm{jk}}=\mathrm{a}_{\mathrm{jk}} \quad \text { if } d\left(v_{\mathrm{j}}, v_{\mathrm{k}}\right) \leq L_{\mathrm{jk}} \\
& \beta_{\mathrm{jk}}=\mathrm{g}_{\mathrm{jk}}^{-1}\left[\mathrm{~d}\left(\mathrm{v}_{\mathrm{j}}, \mathrm{v}_{\mathrm{k}}\right)\right] \quad \text { if } \mathrm{L}_{\mathrm{jk}}>\mathrm{d}\left(\mathrm{v}_{\mathrm{j}}, \mathrm{v}_{\mathrm{k}}\right) \text {. }
\end{aligned}
$$

(a) The condition

$$
\mathrm{d}\left(\mathrm{v}_{\mathrm{j}}, \mathrm{v}_{\mathrm{k}}\right) \leq \mathrm{g}_{\mathrm{jk}}(\mathrm{z}), \mathrm{z} \in\left[\mathrm{a}_{\mathrm{jk}}, \mathrm{b}_{\mathrm{jk}}\right]
$$

is equivalent to

$$
\beta_{\mathrm{jk}} \leq \mathrm{z}, \mathrm{z} \in\left[\mathrm{a}_{\mathrm{jk}}, \mathrm{b}_{\mathrm{jk}}\right] .
$$


(b) If $\mathrm{j}=\mathrm{k}=\mathrm{i}, \beta_{\mathrm{jk}}=\beta_{\mathrm{ii}}=\mathrm{f}_{\mathrm{i}}(0)$.

(c) If $\{\mathrm{j}, \mathrm{k}\} \cap \mathrm{MS} \neq \phi, \beta_{\mathrm{jk}}<\mathrm{f}^{*}$.

The following additional notation is useful:

$$
\begin{aligned}
\beta^{\prime} & =\max \left[\beta_{j k}:\{j, k\} \subset M P, j<k\right] \text { if }|M P| \geq 2 \\
\beta^{\prime} & =-\infty \text { if }|M P|=1 \\
\beta & =\max \left[\beta_{j k}:\{j, k\} \subset M, j<k\right] \\
\gamma^{\prime} & =\max \left[\beta_{j k}:\{j, k\} \subset M P, j \leq k\right] \\
\gamma & =\max \left[\beta_{j k}:\{j, k\} \subset M, j \leq k\right] .
\end{aligned}
$$

We note that $\alpha^{\prime} \leq \alpha, \beta^{\prime} \leq \beta, \gamma^{\prime} \leq \gamma, \gamma^{\prime}=\max \left(\alpha^{\prime}, \beta^{\prime}\right)$, and $\gamma=\max (\alpha, \beta)$, where the identities for $\gamma^{\prime}$ and $\gamma$ are due to Remark 2(b); also, $\eta \leq \eta^{\prime}$.

Some extra definitions are convenient. Given any $y \in T$ and nonnegative number $r$ define $N(y, r)=\{x \in T$ : $d(x, y) \leq r\}$, and call $N(y, r)$ a neighborhood with center $y$ and radius $r$. Given any $u, v \in T$ define $L(u, v)=\{x \epsilon$ $T: d(u, x)+d(x, v)=d(u, v)\}$; intuitively, $L(u, v)$ is the unique imbedded path joining $u$ and $v$, and has "length" $d(u, v)$.

We say that a subset $S$ of $T$ is convex (or connected) if $L(u, v) \subset S$ for every $u, v \in S$. HORN [6] proves a "pair-wise intersection" property for trees which, slightly modified, is the foundation of the analysis to follow. The result states that "A collection of subtrees has at least one common node if and only if every pair of (these) subtrees has at least one common node." Following Horn's result, Chan and Francis [1] give a different proof of a quite similar result: the intersection of all the members of a finite collection of convex (and compact) subsets of an imbedded tree $T$ is nonempty if and only if every pair-wise intersection of these subsets is nonempty.

It is intuitively appealing, and can be proven (see Lemma 1 and Property 10 of reference [3]) that any neighborhood of $T$ is a convex (or connected) set, and is also compact given rather weak assumptions about $T$. Hence as a special case of the pair-wise intersection property of reference [1] we have the following lemma.

Lemma 1. Given neighborhoods $\mathrm{N}\left(\mathrm{y}_{\mathrm{i}}, \mathrm{r}_{\mathrm{i}}\right)$ of $\mathrm{T}, \mathrm{l} \leq \mathrm{i} \leq \mathrm{m}$, the conditions (2), (3), and (4) below are equivalent:

$$
\begin{gathered}
\cap\left\{\mathrm{N}\left(\mathrm{y}_{\mathrm{i}}, \mathrm{r}_{\mathrm{i}}\right): \mathrm{l} \leq \mathrm{i} \leq \mathrm{m}\right\} \neq \phi \\
\mathrm{N}\left(\mathrm{y}_{\mathrm{j}}, \mathrm{r}_{\mathrm{j}}\right) \cap \mathrm{N}\left(\mathrm{y}_{\mathrm{k}}, \mathrm{r}_{\mathrm{k}}\right) \neq \phi, \mathrm{l} \leq \mathrm{j} \leq \mathrm{k} \leq \mathrm{m} \\
\mathrm{d}\left(\mathrm{y}_{\mathrm{j}}, \mathrm{y}_{\mathrm{k}}\right) \leq \mathrm{r}_{\mathrm{j}}+\mathrm{r}_{\mathrm{k}}, \mathrm{l} \leq \mathrm{j} \leq \mathrm{k} \leq \mathrm{m} .
\end{gathered}
$$

We remark that the nontrivial part of the proof of the lemma is showing (3) implies (2). The condition (3) follows immediately from (2), and it is direct to establish the equivalence of (3) and (4).

We study the function $f^{\prime}$ in order to minimize $f$. It is simpler to develop the theory for $f^{\prime}$ than for $f$, and all such theory then applies to $f$. Fortunately we do not need to determine the set MP used in $\operatorname{defining} f^{\prime}$ in order to develop the theory, as we must know $f^{*}$ in order to construct $M P$, and $f^{*}$ is what we are trying to find.

In order to minimize $f^{\prime}$ we study the following equivalent problem:

$$
\begin{aligned}
& \operatorname{minimize} z \\
& \text { subject to } f_{i}\left[d\left(x, v_{i}\right)\right] \leq z, i \in M P \\
& \qquad z \in\left[\alpha^{\prime}, \eta^{\prime}\right] .
\end{aligned}
$$

We comment that $(5 b)$ is justified by Remark $1(b)$.

The following lemma gives conditions equivalent to (5).

Lemмa 2: Each of the conditions (6) through (16), on $\mathrm{z}$, in conjunction with the condition $\mathrm{z} \epsilon\left[\alpha^{\prime}, \eta^{\prime}\right]$, is equivalent to the feasibility of $\mathrm{z}$ in (5):

$\exists \mathrm{x} \rightarrow \mathrm{f}_{\mathrm{i}}\left[\mathrm{d}\left(\mathrm{x}, \mathrm{v}_{\mathrm{i}}\right)\right] \leq \mathrm{z}, \mathrm{i} \in \mathrm{MP}$

$\exists \mathrm{x} \ni \mathrm{d}\left(\mathrm{x}, \mathrm{v}_{\mathrm{i}}\right) \leq \mathrm{f}_{\mathrm{i}}^{-1}(\mathrm{z}), \mathrm{i} \in \mathrm{MP}$ 
$\exists \mathrm{x} \ni \mathbf{x} \in \cap\left\{\mathrm{N}\left(\mathrm{v}_{\mathrm{i}}, \mathrm{f}_{\mathrm{i}}^{-1}(\mathrm{z})\right): \mathrm{i} \in \mathrm{MP}\right\}$

$\mathrm{S}(\mathrm{z}) \equiv \cap\left\{\mathrm{N}\left(\mathrm{v}_{\mathrm{i}}, \mathrm{f}_{\mathrm{i}}^{-1}(\mathrm{z})\right): \mathrm{i} \in \mathrm{MP}\right\} \neq \phi$

$\mathrm{N}\left(\mathrm{v}_{\mathrm{j}}, \mathrm{f}_{\mathrm{j}}^{-1}(\mathrm{z})\right) \cap \mathrm{N}\left(\mathrm{v}_{\mathrm{k}}, \mathrm{f}_{\mathrm{k}}^{-1}(\mathrm{z})\right) \neq \phi,\{\mathrm{j}, \mathrm{k}\} \subset \mathrm{MP}, \mathrm{j} \leq \mathrm{k}$

$\mathrm{d}\left(\mathrm{v}_{\mathrm{j}}, \mathrm{v}_{\mathrm{k}}\right) \leq \mathrm{f}_{\mathrm{j}}^{-1}(\mathrm{z})+\mathrm{f}_{\mathbf{k}}^{-1}(\mathrm{z}),\{\mathrm{j}, \mathrm{k}\} \subset \mathrm{MP}, \mathrm{j} \leq \mathrm{k}$

$\mathrm{d}\left(\mathrm{v}_{\mathrm{j}}, \mathrm{v}_{\mathrm{k}}\right) \leq \mathrm{g}_{\mathrm{jk}}(\mathrm{z}),\{\mathrm{j}, \mathrm{k}\} \subset \mathrm{MP}, \mathrm{j} \leq \mathrm{k}$

$\beta_{\mathrm{jk}} \leq \mathrm{z},\{\mathrm{j}, \mathrm{k}\} \subset \mathrm{MP}, \mathrm{j} \leq \mathrm{k}$

$\alpha^{\prime} \leq \mathrm{z}$

$\beta^{\prime} \leq \mathrm{z}$

$\gamma^{\prime} \leq \mathrm{z}$.

We omit a formal proof of Lemma 2 , as in most cases the equivalence of adjacent conditions is clear. We use the fact that since $f_{i}$ is continuous and strictly increasing it has an inverse function $f_{i}^{-1}$ which also is continuous and strictly increasing. Likewise $g_{j k}$ has an inverse function which is continuous and strictly increasing. The equivalence of (6) and (7) requires $z$ to be in the domain of $f_{i}^{-1}, z \in\left[f_{i}(0), f_{i}\left(\delta_{i}\right)\right]$, which is implied by $z \in\left[\alpha^{\prime}, \eta^{\prime}\right]$. The equivalence of (13) and (14) is due to Remark 2(a). The key equivalence in (5) through (16) is the equivalence of (10), (11), and (12), which is due to Lemma 1.

With $S(z)$ defined by (10), Lemma 2 gives:

Property 1: (a) We have $\gamma^{\prime}=\mathrm{f}^{*}$, and the set of all points $\mathrm{x}^{*}$ minimizing $\mathrm{f}$ is nonempty and consists of $\mathrm{S}\left(\gamma^{\prime}\right)$. (b) With $\mathrm{z}=\gamma^{\prime}$, each of the conditions (5) through (16) is necessary and sufficient for optimality to the minimax problem.

Proof: (a) From Lemma 2, since (6) implies (16) we conclude $\gamma^{\prime}$ is a lower bound on every value of $f$. Using Lemma 2 with $z=\gamma^{\prime}$ and noting that, $\gamma^{\prime} \leq f^{*} \leq \eta^{\prime}, \gamma^{\prime}=\max \left(\alpha^{\prime}, \beta^{\prime}\right)$, so that $\alpha^{\prime} \leq \gamma^{\prime} \leq \eta^{\prime}$, it follows since (16) implies (6) that $\gamma^{\prime}$ is the minimum value of $f$, and that $S\left(\gamma^{\prime}\right)$ is the nonempty set of all points $x^{*}$ minimizing $f$. (b) This part is immediate from (a) and Lemma 2.

Since $\boldsymbol{\gamma}^{\prime}$ depends on $M P$, it generally cannot be computed prior to determining $f^{*}$. Fortunately, we shall see that $\boldsymbol{\gamma}^{\prime}=\gamma ; \gamma$ can be computed.

Property 2: (a) If $\gamma=\alpha=\mathrm{f}_{\mathrm{p}}(0)$, then $\gamma=\mathrm{f}^{*}=\gamma^{\prime}$, and $\mathrm{p} \in$ MP.

(b) If $\gamma=\beta=\beta_{\mathrm{st}}$, with $\mathrm{s}<\mathrm{t}$, then $\gamma=\mathrm{f}^{*}=\gamma^{\prime}$ and $\{\mathrm{s}, \mathrm{t}\} \subset \mathrm{MP}$.

Proof: (a) Property 1 gives $f^{*}=\gamma^{\prime}$, so that $\alpha \leq f^{*}=\gamma^{\prime} \leq \gamma$. Thus $\gamma=\alpha$ implies $\gamma=f^{*}=\gamma^{\prime}$. Further, we know $f_{i}(0)<f^{*}$ for $i \epsilon M S$, so $f_{p}(0)=\gamma=f^{*}$ implies $p \epsilon M P$. (b) Property 1 gives $\gamma^{\prime}=f^{*}$, so $\beta^{\prime} \leq \gamma^{\prime}$ implies $\beta^{\prime} \leq \mathrm{f}^{*}$. For any $\beta_{j k}$ not used in computing $\beta^{\prime}, j \in M S$ or $k \epsilon M S$, so Remark 2 (c) implies $\beta_{j k}<f^{*}$. Thus for every $\beta_{j k}, \beta_{j k} \leq f^{*}$, so that $\beta \leq f^{*}$. Thus $\beta \leq f^{*}=\gamma^{\prime} \leq \gamma=\beta$, so $\gamma=f^{*}=\gamma^{\prime}$. Since $\beta_{s t}=f^{*}$, Remark 2(c) implies $\{s, t\} \cap$ MS $=\phi$, and so $\{s, t\} \subset M P$.

Given $\gamma=f^{*}$ we now proceed to characterize the minima of $f$. Since $\gamma=\max (\alpha, \beta)$, it suffices in turn to consider the cases $\gamma=\alpha$ and $\gamma=\beta$.

Property 3: If $\gamma=\mathrm{f}_{\mathrm{p}}(0)$ for some $\mathrm{p} \epsilon \mathrm{M}$, then $\mathrm{v}_{\mathrm{p}}$ is the unique minimum of $\mathrm{f}$ and $\mathrm{p} \epsilon \mathrm{MP}$.

Proof: Property 2 gives $\gamma=\gamma^{\prime}$ and $p \in M P$. Thus, by Property $1, S(\gamma)=S\left(\gamma^{\prime}\right)$ is the nonempty set of minima of $f$. As $\gamma^{\prime}=f_{\mathrm{p}}(0), f_{p}^{-1}\left(\gamma^{\prime}\right)=0$, so the definition of $S\left(\boldsymbol{\gamma}^{\prime}\right)$ gives

$$
\phi \neq S(\gamma)=S\left(\gamma^{\prime}\right) \subset N\left(v_{p}, f_{p}^{-1}\left(\gamma^{\prime}\right)\right)=\left\{v_{p}\right\}
$$

and hence $v_{p}$ is the unique minimum of $f$.

We now consider the remaining case where $\gamma=\beta_{s t}$ for some $v_{s}$ and $v_{t}$ and $\gamma>\alpha$. Note, with reference to the definition of $\beta_{s t}$ in Remark 2, that when $\gamma=\beta_{s t}>\alpha$, then $\alpha \geq a_{s t}$ implies $\beta_{s t}>a_{s t}$, and thus $\beta_{s t}=$ 
$g_{s t}^{-1}\left[d\left(v_{s}, v_{t}\right)\right]$. The following preliminary remark is useful. (A tangential result needed in the proof is stated and proven in the appendix.)

REMARK 3: Suppose $\gamma>\alpha$, so that for some distinct $\mathrm{v}_{\mathrm{s}}$ and $\mathrm{v}_{\mathrm{t}}$ with $\mathrm{s}<\mathrm{t}$,

$$
\gamma=\beta_{\mathrm{st}}=\mathrm{g}_{\mathrm{st}}^{-1}\left[\mathrm{~d}\left(\mathrm{v}_{\mathrm{s}}, \mathrm{v}_{\mathrm{t}}\right)\right] .
$$

The following conclusions may be drawn.

(a) We have

$$
\begin{gathered}
\mathrm{f}_{\mathrm{s}}^{-1}(\gamma)+\mathrm{f}_{\mathrm{t}}^{-1}(\gamma)=\mathrm{g}_{\mathrm{st}}(\gamma)=\mathrm{d}\left(\mathrm{v}_{\mathrm{s}}, \mathrm{v}_{\mathrm{t}}\right) \\
\min \left[\mathrm{f}_{\mathrm{s}}^{-1}(\gamma), \mathrm{f}_{\mathrm{t}}^{-1}(\gamma)\right]>0 .
\end{gathered}
$$

(b) For some $\mathrm{x}^{*} \epsilon \mathrm{L}\left(\mathrm{v}_{\mathrm{s}}, \mathrm{v}_{\mathrm{t}}\right)$,

$$
\mathrm{d}\left(\mathrm{v}_{\mathrm{s}}, \mathrm{x}^{*}\right)=\mathrm{f}_{\mathrm{s}}^{-1}(\gamma)
$$

(c) Let $\mathrm{x}^{*} \epsilon \mathrm{L}\left(\mathrm{v}_{\mathrm{s}}, \mathrm{v}_{\mathrm{t}}\right)$ satisfy $(20)$. Then we have $\mathrm{v}_{\mathrm{s}} \neq \mathrm{x}^{*} \neq \mathrm{v}_{\mathrm{t}}$,

$$
\mathrm{d}\left(\mathrm{x}^{*}, \mathrm{v}_{\mathrm{t}}\right)=\mathrm{f}_{\mathrm{t}}^{-1}(\gamma)
$$

and

$$
\mathrm{I}_{\mathrm{st}} \equiv \mathrm{N}\left(\mathrm{v}_{\mathrm{s}}, \mathrm{f}_{\mathrm{s}}^{-1}(\dot{\gamma})\right) \cap \mathrm{N}\left(\mathrm{v}_{\mathrm{t}}, \mathrm{f}_{\mathrm{t}}^{-1}(\gamma)\right)=\left\{\mathrm{x}^{*}\right\}
$$

Proof. (a) Equation (18) follows immediately by applying $g_{s t}$ to (17). Since $\gamma>\alpha, \gamma>f_{s}(0)$ and $\gamma>f_{t}(0)$, so $f_{s}^{-1}(\gamma)>0$ and $f_{t}^{-1}(\gamma)>0$, establishing (19).

(b) From (a) we have $0<f_{s}^{-1}(\gamma)<d\left(v_{s}, v_{t}\right)$, so continuity considerations and the intermediate value theorem, as discussed in reference 2, assure the existence of $x^{*}$ satisfying (20).

(c) Since $x^{*} \epsilon L\left(v_{s}, v_{t}\right)$, from (a) we have

$$
d\left(v_{s}, x^{*}\right)+d\left(x^{*}, v_{t}\right)=d\left(v_{s}, v_{t}\right)=f_{s}^{-1}(\gamma)+f_{t}^{-1}(\gamma) .
$$

Together (20) and (23) give (21). From (20) and (21), $x^{*} \in I_{s t}$. Due to the comment of the appendix, on identifying $x, r_{s}$, and $r_{t}$ with $x^{*}, f_{s}^{-1}(\gamma)$, and $f_{t}^{2-1}(\gamma)$ respectively, and using (20), (21), and the fact that $x^{*} \epsilon$ $L\left(v_{s}, v_{t}\right)$, we conclude that if $y \in I_{s t}$ then $\mathrm{y}=x^{*}$. Thus (22) is true. Further, (19), (20), and (21) give $v_{s}+$ $x^{*}=v_{t}$.

We now employ the remark.

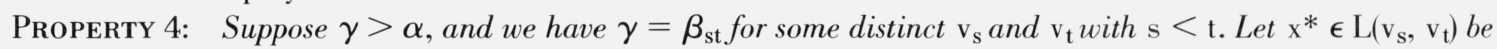
such that $\mathrm{d}\left(\mathrm{v}_{\mathrm{s}}, \mathrm{x}^{*}\right)=\mathrm{f}_{\mathrm{s}}^{-1}(\gamma): x^{*}$ is the unique minimum of $\mathrm{f}$, and $\mathrm{v}_{\mathrm{s}} \neq \mathrm{x}^{*} \neq \mathrm{v}_{\mathrm{t}}$. Also, $\{\mathrm{s}, \mathrm{t}\} \subset \mathrm{MP}$.

Proof. Property 2 gives $\gamma=\gamma^{\prime}$ and $\{s, t\} \subset M P$. Thus from Property 1 , the definition of $S\left(\gamma^{\prime}\right)$, and Remark 3, we have $\phi \neq S(\gamma)=S\left(\gamma^{\prime}\right) \subset N\left(\mathrm{v}_{s}, f_{s}^{-1}(\gamma)\right) \cap N\left(v_{t}, \mathrm{f}_{t}^{-1}(\gamma)\right)=\left\{x^{*}\right\}$, and hence $x^{*}$ is the unique minimum of $f$. Remark 3 also gives $v_{t} \neq x^{*} \neq v_{s}$.

Parenthetically, we observe that when $d\left(v_{j}, v_{k}\right) \leq L_{j k}$, Remark 2 gives $\beta_{j k}=\max \left[f_{j}(0), f_{k}(0)\right]$, so that $\beta_{j k}$ $\leq \alpha$. Thus with

$$
\beta^{*} \equiv\left\{\begin{array}{l}
-\infty \text { if } d\left(v_{j}, v_{k}\right) \leq L_{j k} \text { for all pairs }(j, k) \text { for which } 1 \leq j<k \leq m \\
\max \left\{\beta_{j k}:\{j, k\} \subset M, j<k, L_{j k}<d\left(v_{j}, v_{k}\right)\right\} \text { otherwise }
\end{array}\right.
$$

we have $\gamma=\max \left(\alpha, \beta^{*}\right)$, a fact that may possibly permit $\gamma$ to be computed more efficiently than by using $\gamma=$ $\max (\alpha, \beta)$.

\section{Concluding Remarks}

To summarize our analysis, all of the basic results evolve from Lemma 2, which in turn relies upon the pair-wise intersection property of Lemma 1. Given $\gamma=\gamma^{\prime}$, the equivalent conditions of Lemma 2 immediately imply that $\gamma=f^{*}$, and lead naturally to procedures (Properties 3 and 4) for computing the unique minimum. 
Dearing studies properties of the minimax problem for more general types of distances (e.g., normderived distances in $R^{n}$ ) than the one we consider (which is not norm-derived), and presents a number of properties, including a proof that $\gamma \leq f^{*}$. His analysis establishes $f$ is strict quasiconvex, and can be adapted to show that $f$ has a unique minimum and to provide a procedure (which we state in Properties 3 and 4) for computing the minimum. When distances are rectilinear between pairs of points in the plane, he uses a version of the pair-wise intersection property to show $\gamma=f^{*}$; also he points out that the version given by Horn can be used to show $\gamma=f^{*}$ for the problem we consider.

The major difference between our development and Dearing's is the way in which all our basic results evolve naturally from Lemma 2. This evolution in turn entails proofs different from Dearing's. In addition, we believe Remark 2, Lemma 2, and Properties 1 and 2, to be new. Also, we remark that our analysis can be used readily to establish that $\gamma=f^{*}$ when distances are (a) rectilinear between pairs of points in the plane or (b) Tchebyshev between pairs of points in real $p$-space, $p \geq 1$; for these cases distinct global minima may exist. That $\gamma=f^{*}$ in cases (a) and (b) has previously been established in different ways by Dearing [4], and Goldman [5] respectively. Properties 3 and 4 can be modified to provide precedures for constructing all alternative global minima.

Finally, while the results of this paper have been presented for the case where $T$ is a tree network, we remark, as pointed out by a referee, that a number of the results are in fact more general. In particular, if we take $T$ to be a metric space with metric $d$, assume that each term $\delta_{i}$ is well-defined (which will be the case provided $T$ is a compact metric space), and assume the condition (4) implies (3) and (3) implies (2) (equivalent to changing Lemma 1 to an hypothesis), then all of the results of the paper, with the exception of Remarks 3(b) and (c), and Property 4, are true. Property 4 is true if the second and third sentences are replaced by the following one: Every point in $S(\gamma)$, and at least one point $x^{*}$ in the nonempty set $N\left(v_{s}, f_{s}^{-1}(\gamma)\right) \cap N\left(v_{t}, f_{t}^{-1}(\gamma)\right)$, is a minimum of $f$. Also, we remark, as pointed out by a referee, that the assumption that (3) implies (2) is much stronger than the assumption that (4) implies (3). The latter assumption is true for any connected network or, more generally, for any pathwise-connected metric space.

\section{Appendix}

Here we state and prove an expanded form of Remark 2. Also we state and prove a comment needed in the proof of Remark 3.

Remark 2. Let $\{\mathrm{j}, \mathrm{k}\} \subset \mathrm{M}$ with $\mathrm{j} \leq \mathrm{k}$. Define the function $\mathrm{g}_{\mathrm{jk}}$ with domain $\left[\mathrm{a}_{\mathrm{jk}}, \mathrm{b}_{\mathrm{jk}}\right]$ by

$$
\mathrm{g}_{\mathrm{jk}}(\mathrm{z})=\mathrm{f}_{\mathrm{j}}^{-1}(\mathrm{z})+\mathrm{f}_{\mathrm{k}}^{-1}(\mathrm{z}),
$$

where

$$
\begin{gathered}
a_{j k} \equiv \max \left[f_{j}(0), f_{k}(0)\right] \\
b_{j k} \equiv \min \left[f_{j}\left(\delta_{j}\right), f_{k}\left(\delta_{k}\right)\right] .
\end{gathered}
$$

The following assertions are true.

(a) $\left[\mathrm{a}_{\mathrm{jk}}, \mathrm{b}_{\mathrm{jk}}\right] \neq \phi$.

(b) $\mathrm{g}_{\mathrm{jk}}$ is strictly increasing and continuous, and has range $\left[\mathrm{L}_{\mathrm{jk}}, \mathrm{U}_{\mathrm{jk}}\right]$, where

$$
\begin{array}{rlrl}
0<\mathrm{L}_{\mathrm{jk}} & \equiv \mathrm{f}_{\mathrm{j}}^{-1}\left[\mathrm{f}_{\mathrm{k}}(0)\right]<\delta_{\mathrm{j}} & & \text { if } \mathrm{f}_{\mathrm{j}}(0)<\mathrm{f}_{\mathrm{k}}(0), \\
\mathrm{L}_{\mathrm{jk}} & \equiv 0 & & \text { if } \mathrm{f}_{\mathrm{j}}(0)=\mathrm{f}_{\mathrm{k}}(0), \\
0<\mathrm{L}_{\mathrm{jk}} & \equiv \mathrm{f}_{\mathrm{k}}^{-1}\left[\mathrm{f}_{\mathrm{j}}(0)\right]<\delta_{\mathrm{k}} & & \text { if } \mathrm{f}_{\mathrm{j}}(0)>\mathrm{f}_{\mathrm{k}}(0), \\
\delta_{\mathrm{j}}<\mathrm{U}_{\mathrm{jk}} & \equiv \mathrm{f}_{\mathrm{k}}^{-1}\left[\mathrm{f}_{\mathrm{j}}\left(\delta_{\mathrm{j}}\right)\right]+\delta_{\mathrm{j}}<\delta_{\mathrm{k}}+\delta_{\mathrm{j}} & & \text { if } \mathrm{f}_{\mathrm{j}}\left(\delta_{\mathrm{j}}\right)<\mathrm{f}_{\mathrm{k}}\left(\delta_{\mathrm{k}}\right), \\
\mathrm{U}_{\mathrm{jk}} & \equiv \delta_{\mathrm{j}}+\delta_{\mathrm{k}} & \text { if } \mathrm{f}_{\mathrm{j}}\left(\delta_{\mathrm{j}}\right)=\mathrm{f}_{\mathrm{k}}\left(\delta_{\mathrm{k}}\right), \\
\delta_{\mathrm{k}}<\mathrm{U}_{\mathrm{jk}} & \equiv \mathrm{f}_{\mathrm{j}}^{-1}\left[\mathrm{f}_{\mathrm{k}}\left(\delta_{\mathrm{k}}\right)\right]+\delta_{\mathrm{k}}<\delta_{\mathrm{j}}+\delta_{\mathrm{k}} & \text { if } \mathrm{f}_{\mathrm{j}}\left(\delta_{\mathrm{j}}\right)>\mathrm{f}_{\mathrm{k}}\left(\delta_{\mathrm{k}}\right) .
\end{array}
$$


(c) $\mathrm{d}\left(\mathrm{v}_{\mathrm{j}}, \mathrm{v}_{\mathbf{k}}\right)<\mathrm{U}_{\mathbf{j k}}$.

(d) The inverse function of $\mathrm{g}_{\mathrm{jk}}, g_{\mathrm{jk}}^{-1}$, exists, is strictly increasing and continuous, has domain $\left[\mathrm{L}_{\mathrm{jk}}, \mathrm{U}_{\mathrm{jk}}\right]$ and range $\left[\mathrm{a}_{\mathrm{jk}}, \mathrm{b}_{\mathrm{jk}}\right]$.

(e) Define $\beta_{\mathrm{jk}}$ by

$$
\begin{array}{ll}
\beta_{\mathrm{jk}}=\mathrm{a}_{\mathrm{jk}} & \text { if } \mathrm{d}\left(\mathrm{v}_{\mathrm{j}}, \mathrm{v}_{\mathrm{k}}\right) \leq \mathrm{L}_{\mathrm{jk}}, \\
\boldsymbol{\beta}_{\mathrm{jk}}=\mathrm{g}_{\mathrm{jk}}^{-1}\left[\mathrm{~d}\left(\mathrm{v}_{\mathbf{j}}, \mathrm{v}_{\mathbf{k}}\right)\right] & \text { if } \mathrm{L}_{\mathrm{jk}}<\mathrm{d}\left(\mathrm{v}_{\mathrm{j}}, \mathrm{v}_{\mathrm{k}}\right) .
\end{array}
$$

The condition

$$
\mathrm{d}\left(\mathrm{v}_{\mathrm{j}}, \mathrm{v}_{\mathrm{k}}\right) \leq \mathrm{g}_{\mathrm{jk}}(\mathrm{z}), \mathrm{z} \in\left[\mathrm{a}_{\mathrm{jk}}, \mathrm{b}_{\mathrm{jk}}\right]
$$

is equivalent to

$$
\beta_{\mathrm{jk}} \leq \mathrm{z}, \mathrm{z} \in\left[\mathrm{a}_{\mathrm{jk}}, \mathrm{b}_{\mathrm{jk}}\right]
$$

(f) If $\mathrm{j}=\mathrm{k}=\mathrm{i}, \beta_{\mathrm{jk}}=\beta_{\mathrm{ii}}=\mathrm{f}_{\mathrm{i}}(0)$.

(g) If $\{\mathrm{j}, \mathrm{k}\} \cap \mathrm{MS} \neq \phi, \beta_{\mathrm{jk}}<\mathrm{f}^{*}$.

Proof: (a) For $i \in\{j, k\}, f_{i}^{-1}$ has domain $\left[f_{i}(0), f_{i}\left(\delta_{i}\right)\right]$. As the domain of $g_{j k}$ is the intersection of the domains of $f_{j}^{-1}$ and $f_{k}^{-1}$, the domain of $g_{j k}$ is thus $\left[a_{j k}, b_{j k}\right]$. Also, $\alpha<\eta$ implies $a_{j k}<b_{j k}$, so $\left[a_{j k}, b_{j k}\right] \neq \phi$ by Remark $1(\mathrm{c})$.

(b) It is well-known that a sum of strictly increasing, continuous functions is strictly increasing and continuous, implying in turn that the range of $g_{j k}$ is $\left[g_{j k}\left(a_{j k}\right), g_{j k}\left(b_{j k}\right)\right]$.

Due to the similarity of the various cases of this part of the proof, we consider only the cases of $f_{j}(0)<$ $f_{k}(0)$, where $L_{j k}$ is concerned, and $f_{j}\left(\delta_{j}\right)<f_{k}\left(\delta_{k}\right)$, where $U_{j k}$ is concerned. Subcases not considered are treated similarly.

When $f_{j}(0)<f_{k}(0)<f_{j}\left(\delta_{j}\right), f_{k}(0)$ is in the range of $f_{j}$, so $L_{j k}=f_{j}^{-1}\left[f_{k}(0)\right]$ is well-defined. Also $0=$ $f_{j}^{-1}\left[f_{j}(0)\right]<f_{j}^{-1}\left[f_{k}(0)\right]=f_{j}^{-1}\left[f_{k}(0)\right]+f_{k}^{-1}\left[f_{k}(0)\right]=g_{j k}\left[f_{k}(0)\right]=g_{j k}\left(a_{j k}\right)=L_{j k}=f_{j}^{-1}\left[f_{k}(0)\right]<f_{j}^{-1}\left[f_{j}\left(\delta_{j}\right)\right]=\delta_{j}$.

When $f_{k}(0)<f_{j}\left(\delta_{j}\right)<f_{k}\left(\delta_{k}\right), f_{j}\left(\delta_{j}\right)$ is in the range of $f_{k}$, so $f_{k}^{-1}\left[f_{j}\left(\delta_{j}\right)\right]$ is well-defined. Also, $\delta_{j}=f_{j}^{-1}\left[f_{j}\left(\delta_{j}\right)\right]$ $+f_{k}^{-1}\left[f_{k}(0)\right]<f_{j}^{-1}\left[f_{j}\left(\delta_{j}\right)\right]+f_{k}^{-1}\left[f_{j}\left(\delta_{j}\right)\right]=g_{j k}\left[f_{j}\left(\delta_{j}\right)\right]=g_{j k}\left(b_{j k}\right)=U_{j k}=\delta_{j}+f_{k}^{-1}\left[f_{j}\left(\delta_{j}\right)\right]<\delta_{j}+f_{k}^{-1}\left[f_{k}\left(\delta_{k}\right)\right]=\delta_{j}$ $+\delta_{k}$.

(c) From (b), $\min \left(\delta_{j}, \delta_{k}\right)<\mathrm{U}_{j k}$. From the definition of $\delta_{j}$ and $\delta_{k}, d\left(v_{j}, v_{k}\right) \leq \min \left(\delta_{j}, \delta_{k}\right)$, and so $d\left(v_{j}, \mathrm{v}_{k}\right)$ $<\mathrm{U}_{j k}$.

(d) Since $g_{j k}$ is strictly increasing and continuous, it has an inverse function, $g_{j k}^{-1}$, which is also strictly increasing and continuous. The domain of $g_{j k}^{-1}$ is the range of $g_{j k}$, and the range of $g_{j k}^{-1}$ is the domain of $g_{j k}$.

(e) If $d\left(v_{j}, v_{k}\right) \leq L_{j k}$, then the equivalence of the two conditions is immediate (since $L_{j k}$ is the minimum value of $\left.g_{j k}\right)$. When $d\left(v_{j}, v_{k}\right)>L_{j k}$, by part (c) $d\left(v_{j}, v_{k}\right)$ is in the range of $g_{j k}$, in which case applying $g_{j k}^{-1}$ to the first condition gives the second, while applying $g_{j k}$ to the second condition gives the first.

(f) When $j=k=i$, we have $\beta_{j k}=a_{j k}=a_{i i}=f_{i}(0)$.

(g) When $\{j, k\} \cap M S \neq \phi$, the definition of $M S$ gives $b_{j k}=\min \left[f_{j}\left(\delta_{j}\right), f_{k}\left(\delta_{k}\right)\right]<f^{*}$, so as $\beta_{j k} \leq b_{j k}$ we have $\beta_{j k}<f^{*}$. 
Comment: Given that $T$ is an imbedded tree, suppose $\exists x, x \in T$, such that

$$
\begin{aligned}
d\left(v_{i}, x\right) & =r_{i}, \quad i=s, t \\
d\left(v_{s}, v_{t}\right) & =d\left(v_{s}, x\right)+d\left(x, v_{t}\right) .
\end{aligned}
$$

If $y$ is such that

$$
d\left(v_{i}, y\right) \leq r_{i}, \quad i=s, t
$$

then $y=x$.

Proof. Equations (24) and (25) give

$$
d\left(v_{s}, v_{t}\right)=r_{s}+r_{t}
$$

while (26) and the triangle inequality give

$$
d\left(v_{s}, v_{t}\right) \leq d\left(v_{s}, y\right)+d\left(y, v_{t}\right) \leq r_{s}+r_{t} .
$$

From (27) and (28),

$$
d\left(v_{s}, y\right)+d\left(y, v_{t}\right)=r_{s}+r_{t}=d\left(v_{s}, v_{t}\right)
$$

and thus (26) and (29) give

$$
d\left(v_{i}, y\right)=r_{i}, \quad i=s, t .
$$

From (29) we have $y \epsilon L\left(v_{s}, v_{t}\right)$, so since $T$ is an imbedded tree, Lemma 1 of [2] implies $y \in L\left(v_{s}, x\right) \cup L\left(x, v_{t}\right)$. We may assume $y \in L\left(v_{s}, x\right)$ without loss of generality, so that

$$
d\left(v_{s}, x\right)=d\left(v_{s}, y\right)+d(y, x) .
$$

Thus (25) and (31) give

$$
d\left(v_{s}, v_{t}\right)=d\left(v_{s}, y\right)+d(y, x)+d\left(x, v_{t}\right)
$$

Using (27), (30), and (24) with (32) we have

$$
r_{s}+r_{t}=r_{s}+d(y, x)+r_{t}
$$

Thus $d(y, x)=0$, and so $y=x$.

I would like to acknowledge the constructive comments of P. M. Dearing, and of the referees.

\section{References}

[1] Chan, A. W., and Francis, R. L., A round-trip location problem on a tree graph, Trans. Sci. 10, 35-51 (1976).

[2] Dearing, P. M., and Francis, R. L., A minimax location problem on a network, Trans. Sci. 8, 333-343 (1974).

[3] Dearing, P. M., Francis, R. L., and Lowe, T. J., Convex location problems on tree networks, Opns. Res. 24, 628-642 (1976).

[4] Dearing, P. M., Minimax location problems with nonlinear costs. J. Res. Nat. Bur. Stand. (U.S.), 82, 65-72 (July-Aug. 1977).

[5] Goldman, A. J., Notes of lectures given at the NSF-CBMS Regional Conference on Mathematics of Optimal Facility Location, Saint Olaf College, Northfield, Minnesota, June 28-July 2, 1976.

[6] Horn, W. A., Three results for trees, using mathematical induction, J. Res. Nat. Bur. Stand. (U.S.), 76B (Math. Sci.) Nos. 1 \& 2 , 39-45 (Jan.-June 1972). 